\title{
DIREITO AGRÁRIO E O TRATAMENTO DOS CONTRATOS AGRÁRIOS ATÍPICOS
}

\author{
Fabrício Pinto Weiblen* \\ Marcelo Scherer da Silva** \\ Tarso Wayhs Tech*** \\ José Fernando Lutz Colelho****
}

RESUMO: Aborda a necessidade de um tratamento adequado e diferenciado aos contratos agrários atípicos em face das complexas relações que se desenvolvem no meio rural atualmente. Apresenta ainda uma visão crítica a respeito das características e aplicabilidade da legislação agrária no cenário jurídico e propõe alternativas com o objetivo de uma prestação mais eficiente do Direito Agrário na área contratual. PALAVRAS-CHAVE: Contratos agrários atípicos. Legislação agrária. Direito Agrário.

ABSTRACT: It approaches the necessity of a treatment appropriated and singular for non-typical agrarian contracts related to complex relations that are developed through rural ambient nowadays. Reports also a critical vision about the characteristics and application of agrarian legislation in judicial context and suggests alternatives in order to make an efficient application of Agrarian Law in contractual matter.

KEY-WORDS: Non-typical agrarian contracts. Agrarian legislation. Agrarian Law.

\footnotetext{
*Acadêmico do $5^{\circ}$ semestre do curso de Direito Diurno da Universidade Federal de Santa Maria. E-mail: fabriciopw@terra.com **Acadêmico do $5^{\circ}$ semestre do curso de Direito Diurno da Universidade Federal de Santa Maria. E-mail: marcelopagedown@hotmail.com

***Acadêmico do $5^{\circ}$ semestre do curso de Direito Diurno da Universidade Federal de Santa Maria. E-mail: tarsotech@yahoo.com.br

****Mestre em Integração Latino Americana pela Universidade Federal de Santa Maria. Professor da UFSM e da Fadisma. Advogado. Orientador.
} 


\section{INTRODUÇÃO}

O Estatuto da Terra completou, no ano de 2007, quarenta e três anos de vigência. Nesse período, poucas foram suas alterações, tendo em vista a conservação de todos os princípios que nortearam sua implementação em 1964. Da mesma forma, o Decreto 59.566/66, que regula os contratos agrários, não sofreu significativas mudanças desde sua criação a fim de acompanhar os novos institutos negociais que emergem constantemente no campo.

O Estatuto da Terra (Lei 4504/64) foi elaborado com o objetivo de desenvolver uma política agrária em busca de justiça social no campo, da reforma agrária e do crescimento econômico no meio rural. Assim, foi criado um sistema normativolegislativo que visa a facilitar o acesso do indivíduo ao imóvel rural, condicionando o uso da terra à função social da propriedade. Em decorrência deste sistema normativo, dois anos mais tarde entrou em vigor o Decreto 59.566, que veio a regular o Estatuto da Terra e estabelecer normas a respeito dos contratos agrários.

Devido a esse avanço legislativo, o Direito Agrário brasileiro sofreu significativa evolução, principalmente no que se refere às relações sociais no meio rural e ao tratamento dado aos contratos agrários.

A Lei 4504/64 e o Decreto regulamentador fazem menção a apenas duas espécies de contratos: o arrendamento e a parceria rural. Estes são os contratos agrários típicos definidos nas referidas leis, mencionando apenas de forma genérica a existência de outros contratos. Assim é a redação do Artigo 39 do Decreto:

Art 39. Quando o uso ou posse temporária da terra for exercido por qualquer outra modalidade contratual, diversa dos contratos de Arrendamento e Parceria, serão observadas pelo proprietário do imóvel as mesmas regras aplicáveis à arrendatários e parceiros, e, em especial a condição estabelecida no art. 38 supra ${ }^{1}$.

Com o avanço das práticas rurais, o Estatuto da Terra e o Decreto 59.566/66 se tornaram insuficientes para regular as complexas relações sociais modernas o os diversos contratos agrários que decorrem destas relações. A ausência de regulamentação específica, no que diz respeito a uma multiplicidade de negócios jurídicos agrários atípicos $^{2}$, traz à tona uma pluralidade de dúvidas às partes nestes contratos e aos operadores do direto de maneira genérica.

\footnotetext{
${ }^{1}$ Decreto 59.566/66, Art 38.- A exploração da terra, nas formas e tipos regulamentados por êste Decreto, somente é considerada como adequada a permitir ao arrendatário e ao parceiro-outorgado gozar dos benefícios aqui estabelecidos, quando fôr realizada de maneira: (...)

${ }^{2}$ Conforme Álvaro Villaça Azevedo, a utilização da nomenclatura de contratos atípicos parece ser mais adequada do que contratos inominados, uma vez que se referem a contratos que não possuem referência na lei, mas possuem, de fato, nomes próprios.
} 
Desta forma, o presente trabalho tem o objetivo de expor as problemáticas inerentes à inadequação da legislação agrária à conjuntura atual e propor alternativas para uma melhor aplicação dos princípios norteadores do direito agrário nos contratos atípicos deste ramo do direito.

\section{LEGISLAÇÃO AGRÁRIA: CARACTERÍSTICAS E APLICAÇÃO}

O Direito Agrário, por ser um ramo autônomo da ciência jurídica, possui características próprias que se distinguem do Direito Civil comum. Enquanto este tem por base o liberalismo e o individualismo nas relações, com ampla autonomia de vontade, aquele possui um caráter público, com normas obrigatórias e irrenunciáveis.

Toda a legislação de Direito Agrário está assentada sobre três grandes princípios informadores, quais sejam: Função Social da Propriedade ${ }^{3}$, Justiça Social ${ }^{4}$ e Prevalência do Interesse Público ${ }^{5}$. Claramente se denota a divergência acentuada entre os princípios do Direito Civil e os de Direito Agrário.

A legislação agrária possui, ao mesmo tempo, normas de caráter público e privado. Daí se retira que alguns comandos exigidos pelas normas legais não estão postos à disposição das partes. Logo no artigo $2^{\circ}$ e seu parágrafo único do Decreto resta clara a restrição da autonomia de vontade entre as partes, senão vejamos:

Art $2^{\circ}$ Todos os contratos agrários reger-se-ão pelas normas do presente Regulamento, as quais serão de obrigatória aplicação em todo o território nacional e irrenunciáveis os direitos e vantagens nelas instituídos (art.13, inciso IV da Lei $\mathrm{n}^{\circ}$ 4.947-66).

Parágrafo único. Qualquer estipulação contratual que contrarie as normas estabelecidas neste artigo, será nula de pleno direito e de nenhum efeito.

Desta feita, uma vez constatada a aplicação da legislação agrária ao contrato, as partes não poderão estipular a renúncia de qualquer dos direitos ali garantidos, como indenização de benfeitorias, prazos mínimos de cumprimento dos contratos, direito de preferência na aquisição do imóvel, entre outros.

Outra característica importante dos contratos agrários é referente ao meio de prova usado para a comprovação de sua existência. O contrato agrário pode ser provado

\footnotetext{
${ }^{3}$ Constituição Federal, Art. 186. A função social é cumprida quando a propriedade rural atende, simultaneamente, segundo critérios e graus de exigência estabelecidos em lei, aos seguintes requisitos:

I - aproveitamento racional e adequado;

II - utilização adequada dos recursos naturais disponíveis e preservação do meio ambiente;

III - observância das disposições que regulam as relações de trabalho;

IV - exploração que favoreça o bem-estar dos proprietários e dos trabalhadores.

${ }^{4}$ Estatuto da Terra, art. $2^{\circ}$ É assegurada a todos a oportunidade de acesso à propriedade da terra, condicionada pela sua função social, na forma prevista nesta Lei.

Alencar Mello Proença refere que a agricultura, como uma categoria da atividade econômica, não pode ser assim analisada sem que estejam inseridos ao seu conceito os aspectos sociais que a circundam. Por isso, há normas que protegem o interesse social em detrimento do individual.
} 
exclusivamente com testemunhas, independentemente do valor alcançado ${ }^{6}$. Em relação aos contratos de natureza civil, a prova testemunhal só será admitida se o contrato não ultrapassar o valor do décuplo do maior salário mínimo vigente no país ${ }^{7}$.

Diante dessas diferenças, é de fundamental importância saber definir quando um contrato, em um eventual conflito entre as partes, será regulado pelo Estatuto da Terra e o Decreto 59.566/66 ou exclusivamente pelo Código Civil, pois as normas e princípios aplicados não só serão diferentes, mas também serão, muitas vezes, opostos.

Neste aspecto, o Estatuto da Terra não andou bem, uma vez que não há uma clara definição do que seja contrato agrário e, conseqüentemente, quando serão aplicados os princípios exclusivos do Direito Agrário e suas normas de ordem pública. Ou seja, a Lei 4504/64 e o regulamento silenciam a respeito do tema, não gerando uma clara distinção do que seja um contrato civil comum e um contrato propriamente agrário.

Importante salientar que não se pode levar em conta a localização como fator diferenciador. Tal recurso é usado apenas para fins de tributação ${ }^{8}$ pois é possível que se tenha um contrato de locação (Lei 8.245) em uma área não urbana, e, de mesma forma, não será impossível um Contrato Agrário em meio à cidade.

A Jurisprudência se rebate entre as inúmeras lides que lhe são apresentadas envolvendo este tema. A solução adequada no caso concreto é decorrência direta da aplicação das normas agrárias ou do Código Civil. Desta forma, existem diversas demandas em que uma parte procura munir-se da legislação agrarista, afirmando que esta seria aplicável ao contrato em litígio. A outra parte, todavia, defende-se argumentando que o contrato celebrado teria natureza civil. Esta situação é ainda mais recorrente nos contratos agrários atípicos, pois não há nenhuma regulamentação específica sobre os mesmos.

A confusão existente na legislação aplicável aos contratos agrários atípicos é perceptível no Agravo de Instrumento no . 70001937853, julgado na $18^{\text {a }}$ Câmara Cível do Tribunal de Justiça do Rio Grande do Sul. A decisão manteve liminar que concedeu reintegração de posse em virtude de esbulho em imóvel objeto de comodato rural. No caso concreto, o desembargador afirmou que não se tratava de contrato agrário:

\footnotetext{
${ }^{6}$ Decreto 59.566/66, Art. 14. Os contratos agrários, qualquer que seja o seu valor e sua forma poderão ser provados por testemunhas (artigo 92 , $\S 8^{\circ}$, do Estatuto da Terra).

${ }^{7}$ Art. 401. A prova exclusivamente testemunhal só se admite nos contratos cujo valor não exceda o décuplo do maior salário mínimo vigente no país, ao tempo em que foram celebrados.

${ }^{8}$ Código Tributário Nacional, Art. 29. O imposto, de competência da União, sobre a propriedade territorial rural tem como fato gerador a propriedade, o domínio útil ou a posse de imóvel por natureza, como definido na lei civil, localização fora da zona urbana do Município.
} 
Não se está em sede de contrato agrário e por isto não aplicáveis, salvo melhor juízo, seus princípios, a não ser os gerais aplicáveis a todos os contratos, pois a preocupação do legislador, segundo Paulo Torminn Borges, foi a de: 1. "Delinear cada um dos principais institutos de direito agrário, precisamente, evitando perda de tempo futuro nas construções doutrinárias e jurisprudenciais".

Com esta conclusão, o eminente desembargador entende não ser aplicável o prazo de 6 meses do artigo 95, inciso V do Estatuto da Terra após a notificação para o comodatário retirar-se do imóvel, pois não seriam aplicáveis as normas agrárias no negócio jurídico em análise. O julgado também declara que o fato de o comodatário ter colheitas pendentes no imóvel não é motivo suficiente para impedir a reintegração liminar, desconsiderando o artigo 95, inciso I da Lei 4504. Assim, o referido recurso considera um contrato de comodato rural como sendo regulado exclusivamente pelo Código Civil.

O referido entendimento não parece ser o mais acertado. $\mathrm{O}$ fator determinante para a caracterização do contrato agrário é a sua finalidade. A destinação do pacto é o critério adequado para determinar se a relação se insere entre os contratos agrários ou outro ramo do Direito Civil, independente da localização do imóvel situado no negócio jurídico (COELHO, 2006). Desta análise, percebe-se que é perfeitamente possível existirem contratos agrários no meio urbano e contratos civis ou de locação (regidos pela Lei do Inquilinato) no meio rural. Desta forma, cabe ao operador do direito observar se a atividade agrária está presente na destinação principal do negócio jurídico, ou seja, se a prestação do contrato tem cunho agrário específico ou se é uma simples relação de direito civil.

\section{CONTRATOS AGRÁRIOS ATÍPICOS E SUAS PROBLEMÁTICAS}

Os contratos atípicos são derivados da autonomia de vontade e da liberdade de celebrar negócios jurídicos. O Estado não tem poderes para limitar as relações dos indivíduos, desde que não contrariem a lei, os bons costumes e os princípios gerais do direito. Por isso, os contratos atípicos são plenamente aceitos no Direito Civil ${ }^{9}$.

No Direito Agrário não é diferente. Através da previsão legal ${ }^{10}$ de que os contratos agrários atípicos são válidos, desde que não contrariem as leis, os bons costumes, a ordem pública e os princípios gerais do direito agrário, denota-se que

\footnotetext{
${ }^{9}$ Código Civil, Art. 425. É lícito às partes estipular contratos atípicos, observadas as normas gerais fixadas neste Código.

${ }^{10}$ Art 39. Quando o uso ou posse temporária da terra fôr exercido por qualquer outra modalidade contratual, diversa dos contratos de Arrendamento e Parceria, serão observadas pelo proprietário do imóvel as mesmas regras aplicáveis à arrendatários e parceiros, e, em especial a condição estabelecida no art. 38 supra.
} 
qualquer espécie de contrato não regulado pelas leis agrárias, desde que não viole disposições obrigatórias, como a conservação dos recursos naturais e a proteção dada à parte hipossuficiente, pode ser livremente elaborado pelas partes.

No plano fático, todavia, a realização de contratos agrários atípicos demonstra ser uma tarefa extremamente complexa tanto para as partes quanto para os aplicadores do direito ${ }^{11}$. Nos contratos agrários atípicos esta autonomia total de vontade da partes se revela ainda mais temerosa. Qual seria o tratamento adequado dispensado a contratos sem qualquer previsão regulamentadora, mas que, por terem uma finalidade rural, devem obedecer a normas e princípios obrigatórios determinados pela Lei 4504/64 e pelo Decreto 59566/66? A resposta poderia estar na aplicação analógica das normas de ordem pública inseridas nos contratos típicos de parceria e arrendamento rural, conforme preceitua o artigo 39 do Decreto.

Ocorre que, em diversas situações práticas, a simples aplicação das normas imperativas dos contratos típicos não irá satisfazer aos anseios das partes que celebraram um negócio jurídico atípico específico. Ou seja, o objeto do contrato atípico pode não se coadunar com as normas aplicáveis ao arrendamento ou a parceria.

O contrato de pastoreio ou invernagem ilustra bem a questão. Trata-se de pacto onde o proprietário (ou possuidor) recebe animais para engorda em troca de um pagamento mensal. É utilizado normalmente nos períodos entre safras e tem como característica sua exígua duração, não ultrapassando o período de 1 ano. Deste modo, nota-se que os prazos mínimos de 3, 5 ou 7 anos, obrigatórios nos contratos agrários, são inaplicáveis na realidade dos negócios jurídicos de pastoreio.

Assim, está demonstrado que os contratos agrários atípicos representam um todo uno e indivisível de obrigações que necessitam de um tratamento específico na legislação agrária, na busca de um ordenamento jurídico que satisfaça as necessidades das sociedades regionalizadas e complexas.

\section{ALTERNATIVAS PARA UMA APLICAÇÃO MAIS ACERTADA DA LEGISLAÇÃO AGRÁRIA}

A situação atual do tratamento dos contratos agrários atípicos é clara no sentido de que há uma lacuna no tocante a legislação específica que possibilite um regramento de tais negócios jurídicos, de forma a acompanhar a evolução das relações do campo.

\footnotetext{
${ }^{11}$ Segundo Álvaro Villaça Azevedo na obra Teoria Geral dos Contratos Típicos e Atípicos, contratos atípicos são aqueles que não possuem regulamentação específica na lei. O Autor vai além afirmando que os contratos atípicos das relações privadas representam uma liberdade maior para os contratantes em virtude da ausência de lei, o que pode gerar sérios riscos a direitos se esta liberdade extremada não for devidamente controlada.
} 
Assim, muito embora inegável seja a dificuldade de o legislador acompanhar o desenvolvimento e as mudanças das atividades agrárias, em face das inúmeras possibilidades contratuais rurais, dependendo da região do país e de seus usos e costumes, deve-se procurar seguir as referidas mudanças da forma mais efetiva, o que claramente não vem acontecendo.

Para tanto, é necessário refletir acerca de uma alteração na competência para legislar sobre a matéria, de modo a tornar mais célere o referido acompanhamento por parte da legislação que versa as relações rurais. A regulamentação do Direito Agrário, de forma inadequada, só pode ser alterada por Lei Federal. Ocorre que as relações no meio rural são norteadas por usos e costumes regionais, mormente no caso dos contratos agrários atípicos ou inominados, de forma que, ante a extensão do território brasileiro, torna impossível o devido tratamento do tema. Assim, importante seria existir a possibilidade de alteração da matéria de negócios jurídicos agrários por meio de legislação estadual, a fim de que haja uma maior efetividade na regulamentação de tais relações, uma vez que a utilização constante e reiterada de determinado tipo de negócio tenderia a uma padronização de tal negócio, pelo menos no âmbito regional, possibilitando, dessa forma, uma adequação das normas à realidade fática daquela localidade.

Necessária também é a reflexão sobre uma alternativa ao mero tratamento legislativo do tema, haja vista que a mudança citada é de difícil implementação e, embora de relevância seja a análise do maior número de alternativas para a solução da problemática, não é do interesse do presente estudo limitar-se à apresentação de possibilidades remotas para tal fim. Nesse diapasão, cabe igualmente ao Judiciário assumir um papel mais ativo na questão sob exame, de forma que não apenas julgue o certo e o errado conforme a lei, mas sobretudo verifique se o poder discricionário de legislar está cumprindo a sua tarefa de implementar os resultados almejados pelo Direito Agrário, qual sejam, o desenvolvimento econômico do campo, a geração de recursos, entre outros.

Não se deseja atribuir ao Judiciário o poder de criar políticas públicas, mas sim a responsabilidade de outorgar uma maior efetividade àquelas já estabelecidas nas leis constitucionais ou ordinárias. Dessa forma, exige-se um Judiciário que realmente ouse controlar a omissão legislativa no que se refere à atualização da legislação agrária e até mesmo suprir, na medida do possível, tal omissão, enquanto a matéria não for tratada de forma mais objetiva pelo legislador. 
Nesse sentido leciona COELHO (2006, p.86):

Um elemento preponderante nesse sentido é a jurisprudência, através dos arestos emanados dos Tribunais, vem lapidando e dando certos contornos na interpretação dos contratos de arrendamento, parceria rural, e aos atípicos, pois, se o legislativo não institui o novo Estatuto da Terra, evidentemente, pelos inúmeros entraves políticos, cabe ao judiciário (não legislar), mas efetivamente estabelecer procedimentos e soluções eqüitativas nas composições das lides agrárias, principalmente na relação contratual.

Com efeito, tal papel do Poder Judiciário vem sendo cumprido, de certa forma, tendo em vista diversas jurisprudências inovadoras dos Tribunais dos Estados deste país, máxime nas hipóteses de contratos agrários atípicos ou inominados, mas ainda subsistem dúvidas relevantes a serem suprimidas.

Ademais, faz-se necessário a elaboração de normas principiológicas genéricas que sejam adaptáveis a variedade de contratos que possam vir a ser elaborados. Da mesma forma, seria prudente a tipificação dos contratos agrários que já estão consagrados pelos costumes e usos populares, como o comodato rural, o leasing agrário, o contrato do roçado, entre outros.

Por fim, vale dizer que esta proposta não busca desvirtuar os fundamentos do Direito Agrário no âmbito dos contratos agrários atípicos. O que se sugere é uma modernização das normas agraristas para os contratos inseridos neste ramo do direito, sempre respeitando o interesse social, o caráter público das regras e a intervenção estatal, porquanto uma maior regulamentação destes negócios jurídicos gerará a garantia de que os princípios do Direito Agrário serão assegurados, principalmente no que concerne à função social da propriedade e ao progresso econômico e social no campo.

\section{CONSIDERAÇÕES FINAIS}

O Estatuto da Terra e o Decreto 59.566/66, ambos com mais de quarenta anos, representam grande avanço na legislação brasileira, por seus princípios e normas de cunho social que passaram a reger todo o Direito Agrário e pela estruturação de um instrumento político para a modernização rural.

Contudo, com o passar dos anos e a evolução das relações no campo, tornou-se evidente o fato de que suas normas são insuficientes para regulamentar todos os negócios jurídicos advindos do setor agrário.

Nesse cenário, faz-se necessário refletir acerca das distinções entre a matéria de Direito Agrário e a matéria do Direito Civil comum e a aplicação adequada a ser feita 
nos casos concretos. A partir de tais diferenças, entende-se que a melhor opção é a utilização do critério da destinação ou finalidade para decidir sobre o uso das normas agrárias ou civis. Assim, enquanto estas se pautam pela autonomia da vontade, individualismo e liberalismo, aquelas se caracterizam por serem de ordem pública, limitando-se a autonomia da vontade e, em conseqüência, tornando irrevogáveis os direitos nelas positivados.

A despeito da aparente ausência de dúvidas no que diz respeito ao parâmetro para aplicação das diferentes normas, a maior controvérsia reside no próprio Direito agrário, tendo em vista principalmente a insuficiência de normas adequadas para regular os contratos atípicos, uma vez que o legislador praticamente silenciou-se acerca da matéria, citando-a apenas no art. 39 do Decreto.

Nesse contexto, de relevância é o estudo de alternativas à omissão legislativa, visto que as normas que regem os contratos típicos, quais sejam, o arrendamento e a parceria rural, não podem ser aplicadas em sua totalidade aos contratos inominados, como já explicitado. Para tanto, existem possibilidades importantes, porém de duvidosa efetividade, tais como a alteração da competência para legislar sobre as relações rurais do âmbito federal para o estadual.

Além desta, como citado, torna-se imperiosa uma maior participação do Judiciário, a fim de dar um tratamento uniforme à matéria, uma vez que ainda existem equívocos na aplicação e diferenciação entre simples contratos civis e contratos agrários atípicos. A jurisprudência também tem papel relevante na constante tarefa de contornar as deficiências da lei e solucionar os casos concretos da melhor maneira possível, fornecendo a segurança jurídica tão necessária às relações do campo.

Portanto, as inovações são fundamentais no tratamento dos contratos agrários na busca de uma legislação adequada às modernas relações do campo. Deve-se recorrer a todas as alternativas viáveis em Direito para este objetivo ser alcançado. Todavia, os princípios norteadores, as normas de ordem pública e os preceitos constitucionais referentes ao Direito Agrário devem ser preservados, uma vez que se busca apenas uma adequação à realidade moderna e complexa e não um sistema totalmente diferente.

\section{REFERÊNCIAS BIBLIOGRÁFICAS}

AZEVEDO, Álvaro Villaça. Teoria geral dos contratos típicos e atípicos. São Paulo: Atlas, 2004.

GARCIA, Augusto Ribeiro. Estatuto da Terra. Combatida por uns e elogiada por outros, a lei desperta interesse no mundo. Disponível em 
http://www.portaldoagronegocio.com.br/index.php?p=texto\&\&idT=826. Acessado em 25 de setembro de 2007.

BARROSO, Lucas Abreu. Leasing agrário e arrendamento rural com opção de compra. Belo Horizonte: Editora Del Rey, 2001.

BORGES, Antonino Moura. Curso Completo de Direito Agrário. Leme - SP: Edijur, 2005.

COELHO, José Fernando Lutz. Contratos Agrários. Uma Visão Neo-Agrarista. Curitiba: Juruá, 2006.

GARCIA, augusto Ribeiro. Locação de pasto, negócio bom mas sutil. Disponível em http://www.advagroambiental.adv.br/art0000026.htm. Acessado em 30 de setembro de 2007.

OPITZ, Oswaldo e OPITZ, Silvia C. B. Contratos no Direito Agrário. Porto Alegre: Síntese, 2000.

PROENÇA, Alencar Mello. Compêndio de Direito Agrário. Pelotas: EDUCAT, 2007. STRADELLA, Luisina; NAZARIO, Edgardo Rafael e PEROSIO, Mariano. Contratos Agrários.

Disponível

em http://www.acopiadorescba.com.ar/Compendios/contratos/CONTRATOSAGRARIOS.p df. Acessado em 1 de outubro de 2007. 